\title{
PRIMENJENI MODEL PRIHVATANJA TEHNOLOGIJE: ISTRAŽIVANJE UTICAJA FAKTORA MOTIVACIJE ZA KORIŠĆENJE TEHNOLOGIJE ZA KUPOVINU NA INTERNETU KOD GENERACIJE $Z$
}

\section{APPLIED TECHNOLOGY ACCEPTANCE MODEL: RESEARCHING THE IMPACT OF MOTIVATIONAL FACTORS FOR USING ONLINE SHOPPING TECHNOLOGY ON GENERATION Z}

\author{
Petar Masleša, Fakultet tehničkih nauka, Novi Sad
}

Oblast - INDUSTRIJSKI MARKETING I INŽENJERSTVO MEDIJA

\begin{abstract}
Kratak sadržaj - Druga decenija 21. veka obeležila je digitalna transformacija mnogih procesa, između ostalog $i$ kupovine. Kupovina preko interneta donela je mnogo novina u poslovanju i stvorila mnoge mogućnosti kada je poslovanje na internetu $u$ pitanju. Donela je $i$ nove implikacije kad su navike i ponašanje potrošača u pitanju. Kako je u toku smena generacija u radnoj snazi, ali i među potrošačima, važno je istražiti kako se nova generacija, generacija Z, ponaša kao potrošač i korisnik modernih platformi za kupovinu. Istraživanje u ovom radu bavi se problemom kako pripadnici generacije $Z$ percipiraju tehnologiju za kupovinu preko interneta kroz model prihvatanja tehnologije. Predmet rada su pripadnici generacije Z, odnono uticaj faktora motivacije koji utiču na odluku o korišćenju tehnologije za kupovinu na internetu. Cilj rada je da pokaže kako motivacioni faktori utiču na odluku o korišćenju određene platforme kroz prizmu digitalnog marketinga i elektronskog komerca.
\end{abstract}

Ključne reči: Model prihvatanja tehnologije, kupovina preko interneta, generacija $Z$, digitalni marketing

Abstract - The second decade of the 21st century was marked by the digital transformation of many processes, including purchasing. Online shopping has brought many innovations in business and created many opportunities when it comes to online business. It has also brought new implications when it comes to consumer habits and behavior. As the generation shift in the workforce is underway, but also among consumers, it is important to explore how the new generation, Generation $Z$, behaves as a consumer and user of modern shopping platforms. The research in this paper deals with the problem of how Generation $Z$ perceives technology for online shopping through the technology acceptance model. The subjects of the paper are members of Generation $Z$, and the influence of motivational factors that influence the decision to use the selected technology for online shopping. The aim of this paper is to show how motivational factors influence the decision to use a certain platform through the prism of digital marketing and e-commerce.

\section{NAPOMENA:}

Ovaj rad proistekao je iz master rada čiji mentor je bio doc. dr Đorđe Ćelić.
Keywords: Technology acceptance model, online shoping, generation $Z$, digital marketing

\section{UVOD}

Razvoj tehnologije olakšao je mnoge aspekte svakodnevnog života uključujući i kupovinu gotovo svih proizvoda dostupnih na tržištu. Kao i u kupovini $u$ fizičkim prodavnicama, $\mathrm{u}$ internet kupovini su se vremenom pojavili šabloni, mapirale se navike, preferencije i putanja koju kupci prolaze i smatraju povoljnom kako bi na kraju te putanje izvršili krajnji cilj kupovinu.

Još jedan izazov sa kojim su se online biznisi susreli jeste smena generacija kupaca koja je sa sobom donela i promene u navikama, ponašanju i iskustvima, gde generacija predstavlja kohortu ljudi rođenih $\mathrm{u}$ istom vremenskom rasponu, koji dele životno doba, i životnu fazu i koji su oblikovani konkretnim vremenskim periodom (događaji, trendovi, razvojni potencijali $\mathrm{i}$ prilike) [1].

Marketinški i prodajni principi u procesu kupovine su isti, ali došlo je do modifikacije mnogih elemenata kako bi se lakše prolagodili digitalnom okruženju i navikama koje se javljaju kao šabloni. Nephodno je mapriati sve promene i moifikacije u navedenom okruženju kako bi odogovorili na zahtev sve veće potrebe za personalizacijom procesa jer je to jedan od elemenata koji je pokazao najveći stepen uspešnosti kad je prodaja onlajn u pitanju.

\section{DEFINISANJE OSNOVNIH POJMOVA}

Da bi se bolje razumelo istraživanje, važno je definsiati pojmove i elemente koji će biti predmet istraživanja.

\subsection{Elektronska trgovina ili elektronski komerc}

Elektronski komerc (E-komerc) podrazumeva svaku elektrosnki podržanu transakciju između organizacije i eksternih stejkholdera [2]. Najprostije rečeno, e-komerc omogućava izvršavanje transakcija informacija između dve ili više strana koristeći internet [3].

Postoji nekoliko načina na koji načina na koji se može posmatrati elektronski komerc, a jedna od najvažnijih jeste ona na osnovu vrste ekonomskih subjekata između kojih se dešavaju transakcije [4]: 
- Business-to-Business (B2B)

- Business-to-Consumer (B2C)

- Business-to-Employee (B2E)

- Business-to-Government (B2G)

- Business-to-Manager (B2M)

- Consumer-to-Business (C2B)

- Consumer-to-Consumer (C2C)

- Government-to-Business (G2B)

- Government-to-Citizen (G2C)

- Government-to-Government (G2G)

- Peers-to-Peers (P2P)

Pri čemu su B2B i B2C dve najrasprostranjenije i najpopularnije vrste elektronske trgovine.

\subsection{B2C Elektronski komerc}

B2C e-komerc je onlajn transakcija između organizacija, pravnih lica, i fizičkih lica, odnosno krajnjih kupaca i/ili korisnika. B2C e-komerc je ne samo preneo veliki deo naše svakodnevnice u onlajn okruženje već je i privukao dosta istraživača u cilju saznanja šta je to što podstiče tržište da kupuje onlajn [5].

Ova vrsta e-komerca je takođe i ekonomski, tehnološki i kulturni pokretač danas, kako je potreba za jedinstvenom ponudom potrebna kako bi se istakli među konkurencijom koja sve veća na internetu [6].

Već je pomenuto da se pojavio novi pojam u B2C ekomercu, a to je Business-to-Individual (B2I), gde se nastoji napraviti personalizovano iskustvo za svakog individualca u cilju preciznije poruke, ponude i na kraju povećanja konverzija.

\subsection{Digitalni marketing i digitalni marketing u elektronskom komercu}

Digitalni marketing je nezamenljivi deo procesa online prodaje kako predstavlja ulazni i srednji deo prodajnog levka ili funnel-a. Levak predstavlja upravo putanju koju potencijalni kupci prolaze od izaganja inicijalnoj promotivnoj poruci do momenata nakon kupovine kada se kupac nalazi u post-prodajnom delu levka gde se konvertuje $\mathrm{u}$ ambasadora brenda.

Digitalni marketing je nezamenljivi deo procesa online prodaje kako predstavlja ulazni i srednji deo prodajnog levka ili funnel-a.

Povezanost digitalnog marketinga sa e-komercom najjednostvanije može da se prikaže kroz AIDA model u formi levka, gde faze levka predstavljaju različite faze AIDA modela.

$\mathrm{Na}$ početku je hvatanje pažnje potencijalnog kupca, i najveći broj potencijalnih kupaca upravo tu fazu iskusi. Procenat tog broja bude zaintersovano i prelazi u drugu fazu AIDA modela, odnosno drugi nivo levka. Još manji broj dođe do treće faze koja predstavlja želju, a najmanji broj bude dovoljno stimulisan da izvrši akciju i konvertuje se, kako je prikazano na Slici 1 [7].

\subsection{Model prihvatanja tehnologije - TAM}

Koncept se zasniva na teoriji da sposobnosti i elementi sistema izazivaju stimulus kod individue koje pokreću određene motivacione faktore za korišćenje posmatranog sistema, a od tih motivacnih faktora i subjektivne percepcije sistema i njegovih performansi direktno zavisi namera i konkretnog korišćenje sistema.

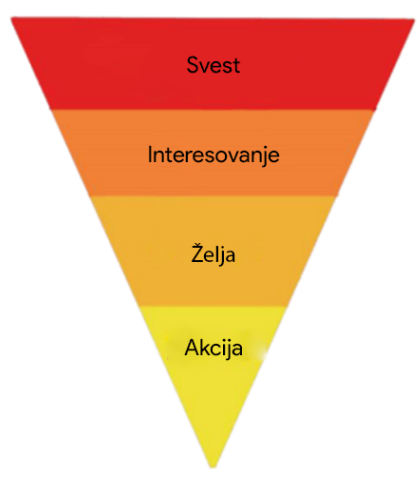

Slika 1. AIDA model u formi levka [7]

Teorija pretpostavlja prihvatanje informacionog sistema od strane individue mereći dva osnovna faktora [8]:

1. Percipiranu lakoću upotrebe sistema

2. Percipiranu korisnost sistema

Gde se percipirana lakoća upotrebe sistema definiše kao stepen do kog individua veruje da bi se korišćenje određenog informacionog sistema odvijalo bez fizičkog $\mathrm{i}$ mentalnog napora.

Percipirana korisnost siteme se definiše kao stepen do kog individua veruje da će korišćenje određenog informacionog sistema poboljšati njegove/njene performanse.

Percipirana korisnost i percpirana lakoća upotrebe informacionog sistema prema Dejvisu zavise, kako je inicijalno prikazano u konceptualnom modelu, zavise od karakteristika, performansi, i sličnih elemenata sistema, koji su definisani u modelu optimizacije stope konverzije kako je prikazano na Slici 2.

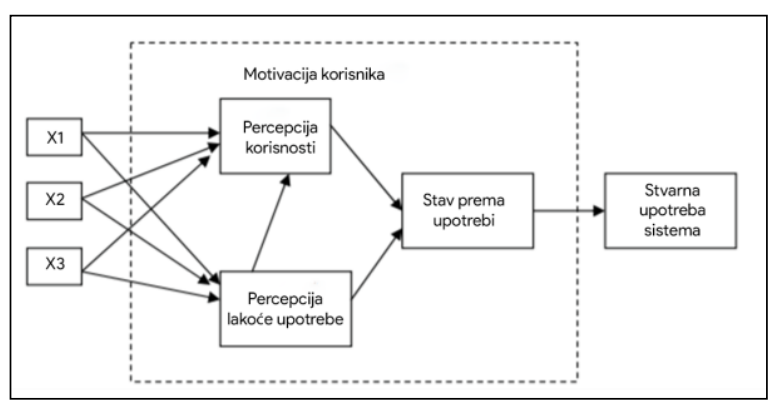

Slika 2. Model prihvatanja tehnologije TAM [8]

\subsection{Generacija $Z$}

Pojam generacije Z, vezuje za generaciju koja došla nakon razvoja World Wide Web-a i koji su odrastali sa ovim fenomenom. Postoji više različitih gornjih granica, uglavnom se definiše da su to ljudi rođeni sredinom 1990ih godina, dvadesetog veka.

Negde postoji čak i donja granica, koja kaže da su to ljudi rođeni od pomenute gornje granice do 2010. godine ili 2012. gofine. Razlike u definisanju jasnog intervala koji će biti prihvaćen jeste momenat prihvatanja tehnologije i razvoja društava u svetu.

Internet je mnogo ranije bio prihvaćen na zapadu nego $u$ istočnoj Evropi i stoga, ne postoji jedna jasna definicija ove generacije.

Najviše autora i istraživača se slaže da su to ljudi rođeni između 1995. godine i 1997. godine, pa ćemo zarad svrhe ovog istraživanja i ovog rada prihvatiti definiciju da su 
pripadnici generacije $\mathrm{Z}$ ljudi rođeni u periodu između 1996. godine i 2012. godine [9].

Mnogi istraživači su se dotakli teme generacije $\mathrm{Z}$ na radnom mestu, kako će to biti jedan od izazova $u$ budućnosti kada postanu radna snaga, međutim ne treba zanemariti ni aspekat posmatranja generacije $\mathrm{Z}$ kao kupaca. Kao i prethodne generacije i generacija $\mathrm{Z}$ ima svoje karakteristike kao kupovna snaga koje su jedinstvene za nju. Stejsi Vud je istraživanjem došla do 4 trenda koja definišu generaciju $\mathrm{Z}$ kao potrošački entitet [10]:

$$
\begin{array}{ll}
\text { - } & \text { Inovacije } \\
\text { - } & \text { Pogodnost } \\
\text { - } & \text { Bezbednost } \\
\text { - } & \text { Eskapizam }
\end{array}
$$

\section{METODOLOGIJA ISTRAŽIVANJA}

Istraživanjem pripadnika generacije $\mathrm{Z}$, pronađeno je da su oni digitalno pismeni i da su odrasli uz tehnologiju pa im je koncept korišćenja tehnologije daleko od nepoznatog. Naprotiv, baš zato što su odrastali i sazrevali paralelno uz napredak tehnologije, vrlo su fluentni u korišćenju tehnologije.

Takođe, istraživanja su pokazala da pripadnici genercije $\mathrm{Z}$, za razliku od prethodnika, ne poznaju alternativu internetu za određene aktivnosti, te da ne percipiraju internet i sve što je danas moguće uraditi preko interneta kao pogodnost i korisnu stvar.

Na osnovu ovih tvrdnji postavljaju se sledeće hipoteze:

H1: Pripadnici generacije $\mathrm{Z}$ tehenologiju za onlajn kupovinu percipiraju kao laku za upotrebu.

H2: Pripadnici generacije $\mathrm{Z}$ ne percipiraju tehnologiju za onlajn kupovinu kao korisnu.

H3: Pripadnici generacije $\mathrm{Z}$ ne percipiraju internet kao pogodnost kad je pretraživanja proizvoda u pitanju.

H4: Motivacioni faktori percipirane lakoće upotrebe i percipirane korisnosti tehnologije za onlajn kupovinu ne doprinose nameri za korišćenje tehnologije.

Za proveru ovih hipoteza $\mathrm{u}$ istraživanju koristio se primenjeni TAM model, odnosno provera pericpirane korisnosti sistema [11], percipirane lakoće korišćenja sistema [12] i namere za korišćenje i preporuku prijateljima i/ili članovima porodice [13]. U cilju proširenja testiranja dodat je još jedan element a to je percipirana pogodnost interneta kao alata za pretragu proizvoda [14] od strane generacije Z.

Za prikupljanje osnovnih informacija o ispitanicima uz demografske podatke korišćeni je testiran model pitanja i ranije korišćen u istraživanjima [15].

Upitnik se sastoji od 5 različitih sekcija, odnosno grupa pitanja, ukupno 21 pitanje. Istraživanje se sprovedeno u periodu od jabuara do marta 2020. godine a upitnik je popunilo 254 ispitanika, od kojih su 248 pripadnici ciljne grupe. Za kreiranje i distribuciju upitnika korišćen je alat Gugl Forme, alatu za kreiranje i dstribuiranje upitnika i anketa onlajn, i upravo tako je i distribuiran upitnik, onlajn, ciljano grupi koja spada svojim godinama $\mathrm{u}$ generaciju $\mathrm{Z}$, kako bi odgovori bili relevantni.
Uzorkovanje je rađeno metodom pogodnosti, plasiran je onima do kojih je bilo najlakše doći, a koji pripadaju ciljnoj grupi.

\section{REZULTATI i DISKUSIJA ISTRAŽIVANJA}

U teorijskom delu je dat prikaz pripadnika generacije $\mathrm{Z}$, prikazano je da su oni digitalno pismeni i da su odrasli uz tehnologiju pa im je koncept korišćenja tehnologije daleko od nepoznatog. Naprotiv, baš zato što su odrastali i sazrevali paralelno uz napredak tehnologije, vrlo su fluentni u korišćenju tehnologije.

$\mathrm{Na}$ osnovu odgovora i analize odgovora ispitanika možemo da vidimo i da li su postavljene hipoteze istinite odnosno neistinite.

Odgovori na prvu grupu pitanja koja se tiče percipirane lakoće korišćenja tehnologije pokazuju visoke ocene ispitanika što potvrđuje teoriju da generacija $\mathrm{Z}$ percipira tehnologiju za onlajn kupovinu kao laku za upotrebu.

Kako je i postavljena hipoteza na osnovu karakternih osobina i opštih karakteristika generacije Z, pripadnici generacije $\mathrm{Z}$ ne percipiraju internet i onlajn kupovinu kao korisnu i kao pogodnost, jer ne znaju za alternativu onlajn aktivnostima.

Ukupno, motivacioni faktori koji se mere u TAM modelu pokazuju da su ispitnici neutralni po pitanju namere za korišćenje i preporuke tehnologije svojim prijateljima $\mathrm{i} / \mathrm{ili}$ članovima porodice.

Tabela 1. Potvrda hipoteza

\begin{tabular}{|l|l}
\hline Hipoteza & Status \\
\hline $\begin{array}{l}\text { H1: Pripadnici generacije Z tehenologiju za } \\
\text { onlajn kupovinu percipiraju kao laku za } \\
\text { upotrebu. }\end{array}$ & Hipoteza prihvaćena \\
\hline $\begin{array}{l}\text { H2: Pripadnici generacije Z ne percipiraju } \\
\text { tehnologiju za onlajn kupovinu kao korisnu. }\end{array}$ & Hipoteza prihvaćena \\
\hline $\begin{array}{l}\text { H3: Pripadnici generacije Z ne percipiraju } \\
\text { internet kao pogodnost kad je pretraživanja } \\
\text { proizvoda u pitanju. }\end{array}$ & Hipoteza prihvaćena \\
\hline $\begin{array}{l}\text { H4: Navedeni motivacioni faktori ne doprinose } \\
\text { nameri za koriśćnje tehnologije. }\end{array}$ & Hipoteza odbijena \\
\hline
\end{tabular}

Ono što se takođe ističe je momenat da gde su ispitanici onlajn okruženje koristiti pre za pretraživanje proizvoda nego za kupovinu na odabranoj platformi. To znači da postoji određena doza anksioznosti i dalje, pretpostavka je jer ispitanici još nisu aktivna radna snaga pa samim tim ne postoji aktivan prihod i kupovna moć. Svakako da slično istraživanje može da se uradi nakon što generacija $Z$ postane radna snaga kako bi se izmerile kupovne navike i ponašanje pri kupovini.

\section{ZAKLJUČAK}

Ovaj rad prikazuje teorijske elemente digitalnog marketinga, B2C e-komerca, marketing miksa, AIDA modela, TAM modela prihvatanja tehnologije i generacije $\mathrm{Z}$ sa ciljem postavke hipoteza o tome kako motivacioni faktori utiču na nameru korišćenja informacionog sistema, kod pripadnika generacije $\mathrm{Z}$.

Optimizacione tehnike, koje se u velikoj meri oslanjaju i zavise od tehnika digitalnog marketinga direktno utiču na percepciju korisnika o brendu i platformi što dalje dovodi do TAM modela. TAM meri percepciju kod publike lakoće upotrebe sistema i korisnosti sistema kao dva motivaciona faktora od kojih zavisi namera za korišćenje 
pa i krajnje konkretno korišćenje tehnologije, ili u ovom slučaju platforme za onlajn kupovinu.

Ova teorijska osnova dobija novi okvir kada se posmatra iz ugla pripadnika generacije $\mathrm{Z}$, koji su fluentni u korišćenju tehnologije i ne percipiraju internet i digitalne tehnologije kao korisne jer je to za njih jedina realnost koju poznaju.

$\mathrm{Na}$ osnovu ovih zaključaka, povezivanja, dedukcija i teorijskih osnova i definicija postavljene su hipoteze koje proveravaju da li pripadnici generacije $\mathrm{Z}$ zaista tehnologiju ne posmatraju kao pogodnost i da li im je zaista toliko laka za upotrebu a sve u kontekstu onlajn kupovine i B2C e-komerca.

Koristeći primenjeni TAM model, odnosno model prihvatanja tehnologije, satavljen je upitnik od već postojećih i ranije korišćenih upitnika, koji ima za cilj prikupljanje odgovora od ispitanika koji su pripadnici generacije $\mathrm{Z}$ kako bi se dobili odgovori na postavljene hipoteze.

Istraživanje je pokazalo da generacija $\mathrm{Z}$ percipira tehnologiju platformi za onlajn kupovinu kao laku za upotrebu, ali internet i e-komerc platforme ne percipiraju kao korisne, ali razlog za to se ne može sa preciznošću utvrditi $u$ ovom istraživnju i to može biti smernica za istraživanje u budućnosti.

Relevantnost ovog rada, još jednom, ogleda se u činjenici da elektronsko poslovanje konsntanto mora da se razvija, da prati trendove $\mathrm{u}$ tehnologiji i estetici, da mapira ponašanje $\mathrm{i}$ navike svojih kupaca, a generacija $\mathrm{Z}$ je generacija koja već sada a i u budućnosti će definisati trendove $\mathrm{u}$ onlajn kupovini, $\mathrm{i}$ te trendove treba mapirati $\mathrm{i}$ optimizovati poslovanje prema njima što pre.

\section{LITERATURA}

[1] M. McCrindle and E. Wolfinger, ABC of XYZ: Understanding The Global Generations, Sydney: UNSW Press, 2011.

[2] D. Chaffey, E-business and E-commerce Management: Strategy, Implementation and Practice, Pearson Education, 2009.

[3] R. Kalakota and A. B. Whinston, Electronic Commerce: A Manger's Guide, Addison-Wesley, 1997.

[4] R. Nemat, "Taking a look at different types of ecommerce," World Applied Programming, pp. 100104, 2011.

[5] L. Qiu and L. Dong, "Applying TAM in B2C ECommerce Research: An Extended Model," TSINGHUA SCIENCE AND TECHNOLOGY, pp. 265-272, 2008.

[6] D. Rosaci and G. Sarnè, "Multi-agent technology and ontologies to support personalization in B2C Ecommerce," Electronic Commerce Research and Applications, 2013.

[7] A. Sapian and M. Vyshnevska, "The Marketing Funnel As An Effective Way Of The Business Strategy," The art of scientific mind, pp. 16-18, 2019.
[8] F. D. Davis, “A Technology Acceptence Model for Empirically Testing New End-User Information Systems: Theory and Results," Doctoral Dissertation, Sloan School of Management, MIT, 1986.

[9] M. Dimock, "Defining generations: Where Millennials end and Generation $\mathrm{Z}$ begins," https://www.pewresearch.org/, 17 January 2019. [Online].

Available: https://www.pewresearch.org/facttank/2019/01/17/where-millennials-end-andgeneration-z-begins/.

[10] S. Wood, "Generation $\mathrm{Z}$ as consumers: trends and innovation," Institute for Emerging Issues: NC State University, pp. 7767-7779, 2013.

[11] D. M. Szymanski and H. T. Richard, "e-Satisfaction: An Initial Examination,” JR, pp. 309-322, 2000.

[12] J. J. Inman and H. Nikolova, "Shopper-Facing Retail Technology: A Retailer Adoption Decision Framework Incorporating Shopper Attitudes and Privacy Concerns," Journal of Retailing, p. 7-28, 2017.

[13] J.-C. Hong, M.-Y. Hwang, T.-Y. Ting, K.-H. Tai and C.-C. Lee, "The Innovativeness and Self-Efficacy Predict the Acceptance of Using iPAD2 as a Green Behavior by the Governmet's Top Administrators," The Turkish Online Journal of Educational Technology, pp. 313-320, 2013.

[14] M. Kukar-Kinney, N. M. Ridgway and K. B. Monroe, "The Relationship Between Consumers' Tendencies to Buy Compulsively and Their Motivations to Shop and Buy on the Internet," Journal of Retailing, pp. 298-307, 2009.

[15] D. Lestari, "Measuring e-commerce adoption behaviour among gen-Z in Jakarta, Indonesia," Economic Analysis and Policy, pp. 103-115, 2019.

\section{Kratka biografija:}

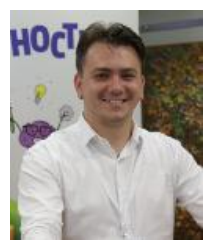

Petar Masleša rođen je u Beogradu 1995. god. Master rad na Fakultetu tehničkih nauka iz oblasti Inženjerskog menadžmenta Primenjeni model prihvatanja tehnologije: Istraživanje uticaja faktora motivacije za korišćenje tehnologije za kupovinu na internetu kod generacije $\mathrm{Z}$ odbranio je 2021.god. kontakt: petarmaslasha@gmail.com 